\title{
Special Issue: COVID-19 as a Challenge on Many Fronts
}

This special edition of the Christian Journal for Global Health takes a multidimensional view of the COVID-19 global pandemic. The articles consider its effects on the individual (Seshadri), healthcare institutions (Seshadri), the community (Millhollin), and the wider economic system (Grills).

As Christians, how do we balance our response to account for the various levels at which it affects the world?

As Christian leaders how can we lead in the face of such an overwhelming situation? Matthew Santhosh Thomas, Training Coordinator and Regional Secretary of the International Christian Medical and Dental Association, starts by offering 12 important trans-cultural aspects of an effective, God-honoring, leadership response to the pandemic.

Indeed, COVID-19 is a wicked and pervasive global health problem as its causes and impacts reach across various sectors, most countries, all organ systems, and all parts of society. The solutions, therefore, need to be multisectoral and to balance the competing interests of the economy, trade, education, social cohesion, religion, and health.

We all need to consider that solutions taken to defeat this disease have significant risks to social determinants of health and have the capacity to cause increased mortality and morbidity in themselves as Nathan Grills from University of Melbourne cautions. An Indian proverb comes to mind: a man is fighting a long battle against a rat infestation in his house. In desperation he pours kerosene over the house, lights a match and very effectively defeats the rat problem. Likewise, in the COVID-19 response, do our strategies to fight COVID-19 involve burning down the house? Is this the only disease with which we have to contend? Likewise, we could respond to the 600,000 seasonal flu deaths using similar approaches as being implemented to prevent COVID-19, but we do not as the cost is too great. We must act decisively to limit the impact of COVID-19, but it is important that we take a broad view of the response taken as individuals, hospitals, and countries.

The necessary social distancing has threatened traditional community, which is in itself so important for health. When the response to COVID-19 requires us to be physically apart, how do we maintain the wholeness which Jordan Millhollin, from Duke Divinity School, argues is dependent on ongoing interdependence and community? This concept is central to the Christian idea of the interdependence within the body of Christ (1 Cor 12). We are profoundly interconnected, even as we are called to be apart, and he suggests ways we need to explore how we can better love each other despite the disruption to community. Apolos Landa from the Sociedad Lucas in Peru then offers a similar reflection on the poison of materialist individualism and the need for interdependence and coresponsibility which reflects the character of God, the Healer.

A number of articles outline practical responses on the global front-lines: The article by Seshadri and John from Christian Medical College (CMC), Vellore, India provides a model for hospitals to take the lead in managing the infection and the risk to their staff. This is very practical and much needed but begs the question as to whether smaller hospitals and health systems lacking the expertise, size, and capability of CMC Vellore would have the personnel, resources, and systems to implement this approach. These same authors present another paper on the importance of presumptive diagnosis based on 
the clinical syndrome in low-resource settings, when PCR testing is less available, and action that must be taken for containment. Then they offer preliminary clinical guidelines for empiric therapies, anticipating the results of clinical trials, in order to mitigate the threat which could overwhelm fragile health systems and deeply affect already vulnerable communities around the world. While keeping watch for results of emerging clinical trials, other low- and middleincome countries would be well advised to cautiously consider the approach outlined by these leaders in the field of virology from one of India's premiere medical colleges.

The response to COVID-19 raises various ethical issues about resource allocation and who is given access to life saving care when resources are overwhelmed. James Haslam and Melody Redman from the UK argue that triage is not a new concept. They critique, from a Christian perspective, the existing ethical frameworks and guidelines and how they apply to management of COVID-19 "surges."

We might think that this pandemic is unprecedented, but we are reminded by Bryan Just from The Center for Bioethics \& Human Dignity that there is, indeed, precedence in history. He explores the role of Christians and the church in responding to previous plagues and pandemics and outlines what we can learn from those responses. He challenges us to follow those who have gone before us and show a radical Christian love - albeit in different ways given the very different contexts we live in today. Vijay Anand Ismayel's article further explores some biblical principles from the story of Nehemiah that can be applied in any context to our radical, measured, and effective response to this pandemic.

It is our hope and prayer that this special issue offers a compelling Christian perspective on the challenges and, yes, opportunities of this unanticipated and vexing pandemic in order to engage the problem with collective strength, wisdom, courage, grace, love, and hope.

Our call for papers, Responding to Epidemics and Pandemics, remains open for submissions for the months ahead as the world is challenged to deal with the global crisis, and results of further research on creative and effective responses emerges, as well as deeper theological reflection on what this means for us as humans in a broken but redeemable world.

\section{Key Resources:}

- $\quad \mathrm{CClH}$ resources \& forum: https://www.ccih.org/cpt resources/covid-19/

- CCIH survey: https://www.ccih.org/covid-19-response-survey-of-fbos/

- Leadership consultations (HFAN): https://www.healthforallnations.com/

- Book \& mission blogs: https://www.medicalmissions.com/coronavirus

- ICMDA Resource Links: https://mailchi.mp/a46dcc104406/covid01?

- Joint Learning Initiative for Faith and Local Communities: https://jliflc.com/covid/

- CUGH resources for educators and researchers: https://myemail.constantcontact.com/COVID-19-Newsletter-Vol-5.html?soid=1112846108446\&aid=AUbGAK-ol U

- FBO resources from CDC: https://www.cdc.gov/coronavirus/2019ncov/community/organizations/index.htm

- Community health fact sheet (in 25 languages): https://protectau.mimecast.com/s/8jexCP7yBIsKOMxPpUzK3Iv?domain=r20.rs6.net 